\title{
Emended description of Actinomyces naes/undii and descriptions of Actinomyces oris sp. nov. and Actinomyces johnsonii sp. nov., previously identified as Actinomyces naes/undii genospecies 1, 2 and WVA 963
}

Correspondence

David Beighton david.beighton@kcl.ac.uk

\author{
Uta Henssge, ${ }^{1}$ Thuy Do, ${ }^{1}$ David R. Radford, ${ }^{1}$ Steven C. Gilbert, ${ }^{1}$ \\ Douglas Clark ${ }^{1}$ and David Beighton ${ }^{1,2}$
}

\footnotetext{
${ }^{1}$ Department of Microbiology, The Henry Wellcome Laboratories for Microbiology and Salivary Research, King's College London Dental Institute, Floor 17, Tower Wing, Great Maze Pond, London SE1 9RT, UK

${ }^{2}$ Biomedical Research Centre, Guy's and St Thomas Foundation Trust Hospital, London SE1 9RT, UK
}

\begin{abstract}
Actinomyces naeslundii is an important early colonizer in the oral biofilm and consists of three genospecies (1, 2 and WVA 963) which cannot be readily differentiated using conventional phenotypic testing or on the basis of 16S rRNA gene sequencing. We have investigated a representative collection of type and reference strains and clinical and oral isolates $(n=115)$ and determined the partial gene sequences of six housekeeping genes (atp $A, r p o B, p g i$, metG, glt $A$ and $g y r A$ ). These sequences identified the three genospecies and differentiated them from Actinomyces viscosus isolated from rodents. The partial sequences of atp $A$ and met $G$ gave best separation of the three genospecies. A. naes/undii genospecies 1 and 2 formed two distinct clusters, well separated from both genospecies WVA 963 and A. viscosus. Analysis of the same genes in other oral Actinomyces species (Actinomyces gerencseriae, A. israelii, A. meyeri, A. odontolyticus and $A$. georgiae) indicated that, when sequence data were obtained, these species each exhibited $<90 \%$ similarity with the $A$. naeslundii genospecies. Based on these data, we propose the name Actinomyces oris sp. nov. (type strain ATCC $27044^{\top}=$ CCUG $34288^{\top}$ ) for A. naes/undii genospecies 2 and Actinomyces johnsonii sp. nov. (type strain ATCC $49338^{\top}$ $=$ CCUG $34287^{\top}$ ) for $A$. naes/undii genospecies WVA 963. A. naes/undii genospecies 1 should remain as $A$. naeslundii sensu stricto, with the type strain ATCC $12104^{\top}=$ NCTC $10301^{\top}$ $=$ CCUG $2238^{\top}$.
\end{abstract}

\section{INTRODUCTION}

Actinomyces naeslundii is a major component of the oral biofilm (Li et al., 2004; Marsh \& Martin, 1999). Identification of the species is problematic, being thoroughly

The GenBank/EMBL/DDBJ accession numbers for the sequences determined in this study are EU667389-EU667411 (16S rRNA gene), EU603149-EU603264 and EU647595-EU647598 (pgi), EU620779EU620894 and EU647585-EU647587 (atpA), EU620895-EU621010, EU647588 and EU647589 ( $\mathrm{g} / \mathrm{t} A$ ), EU621011-EU621126 and EU647590-EU647592 ( $g y r A)$, EU621127-EU621242, EU647593 and EU647594 (metG) and EU621243-EU621358 and EU647599 (rpoB), as detailed in Supplementary Table S3.

Additional single-gene phylogenetic trees, details of primers and details of the oral and non-oral clinical isolates and type and reference strains used in this study, including sequence accession numbers, are available as supplementary material with the online version of this paper. investigated, but not necessarily resolved, by Johnson et al. (1990). Prior to these genetic studies, A. naeslundii and Actinomyces viscosus from humans were identified using a range of biochemical and physiological tests and were differentiated on the basis of catalase production (Ellen, 1976), with numerous serotypes being recognized amongst these strains (Fillery et al., 1978; Gerencser \& Slack, 1976; Putnins \& Bowden, 1993). Using DNA-DNA relatedness, Johnson et al. (1990) demonstrated that strains identified as $A$. naeslundii serotype I were genetically distinct from other strains identified as A. naeslundii or $A$. viscosus and classified these strains as A. naeslundii genospecies 1, while other human strains including $A$. naeslundii serotypes NV, II and III and A. viscosus serotype II were indistinguishable and were classified as A. naeslundii genospecies 2. Strains identified as Actinomyces serotype WVA 963 
constituted another distinct genospecies, WVA 963, while rodent strains identified as A. viscosus serotype I were also genetically distinct. The mean DNA-DNA relatedness between genospecies 1 and genospecies 2 was $37 \%$, that between genospecies 2 and WVA 963 was $31 \%$ and that between genospecies 1 and WVA 963 was $43 \%$ (derived from Table 2 of Johnson et al., 1990). As there were no conventional microbiological phenotypic tests to distinguish between these genotypes, other than serological tests, no novel species were described, but this study clearly demonstrated that human and animal strains were not related.

A. naeslundii genospecies 2 isolates were demonstrated to bind to $N$-acetyl- $\beta$-D-galactosamine and acidic proline-rich proteins and to exhibit an $N$-acetyl- $\beta$-D-galactosaminebinding specificity signified by $N$-acetyl- $\beta$-D-galactosamine-inhibitable coaggregation with specified streptococcal strains. A. naeslundii genospecies 1 also bound to $\mathrm{N}$-acetyl$\beta$-D-galactosamine, but generally not to acidic proline-rich proteins, and possessed another $N$-acetyl- $\beta$-D-galactosamine-binding specificity to a different set of streptococcal isolates (Hallberg et al., 1998). However, the haemagglutination patterns of strains ascribed to genospecies 1 or 2 were not uniform, indicating phenotypic heterogeneity of the surface properties. It is clear that these phenotypic characteristics are not robust enough to permit the ready or convenient identification of A. naeslundii genospecies from oral or clinical samples in disparate laboratories.

Identification of bacteria using 16S rRNA gene sequence comparison is widely used but for some taxa, including viridans streptococci (Hoshino et al., 2005), lactobacilli (Naser et al., 2007) and Veillonella species (Jumas-Bilak et al., 2004), this approach is not reliable, and sequence analysis of other genes, including sodA, pheS, rpoA, rpoB and $d n a K$, has been used to identify members of these genera. $16 \mathrm{~S}$ rRNA gene sequence comparison may not be the most reliable method for identifying the $A$. naeslundii genospecies (Tang et al., 2003). Furthermore, strains of genospecies 1 and 2 exhibit $>99 \% 16 \mathrm{~S}$ rRNA gene sequence similarity and genospecies WVA 963 strains exhibit $>98.5 \%$ similarity with the other two genospecies (see Supplementary Tables S1 and S2, available in IJSEM Online).

We have used partial gene sequence comparison of type and reference strains of $A$. naeslundii genospecies to analyse the relationships between these taxa and propose that $A$. naeslundii genospecies 2 be named Actinomyces oris sp. nov. and A. naeslundii genospecies WVA 963 be named Actinomyces johnsonii sp. nov. and that A. naeslundii genospecies 1 remains as $A$. naeslundii sensu stricto (Thompson \& Lovestedt, 1951); the species can be differentiated by comparison of partial gene sequences of atpA or metG.

\section{METHODS}

Bacterial strains. The type and reference strains of $A$. naeslundii and A. viscosus used in this study are shown in Table 1. Identification of isolates was made on the basis of DNA-DNA relatedness analysis
(Johnson et al., 1990) or agglutination reactions with genospeciesspecific antisera (Putnins \& Bowden, 1993) as indicated. We also examined isolates from human extra-oral infections $(n=12)$ and 77 isolates from oral samples (plaque and carious dentine) to test the robustness of the proposed method of identification. These isolates were identified as $A$. naeslundii- $A$. viscosus from partial $16 \mathrm{~S}$ rRNA gene sequences, obtained with universal primer 357F (Lane, 1991), and exhibited $>99 \%$ sequence similarity when analysed using BLAST (http:// www.ncbi.nlm.nih.gov/blast/Blast.cgi). The clinical and oral isolates are listed in Supplementary Table S3. All isolates were subcultured on fastidious anaerobe agar (FAA; LabM Ltd), grown anaerobically overnight at $37{ }^{\circ} \mathrm{C}$ and preserved in glycerol-containing medium at $-80{ }^{\circ} \mathrm{C}$. Actinomyces gerencseriae ATCC $23860^{\mathrm{T}}$, Actinomyces israelii ATCC $12102^{\mathrm{T}}$, Actinomyces meyeri ATCC $35568^{\mathrm{T}}$, Actinomyces odontolyticus NCTC $9935^{\mathrm{T}}$ and Actinomyces georgiae R11726 were included in the sequence analyses for comparative purposes.

Biochemical tests. All isolates were tested using the API Rapid ID32A kit (bioMérieux) according to the manufacturer's instructions and were tested for aesculin hydrolysis and for acid production from arabinose, cellobiose, fructose, glycogen, inositol, lactose, mannitol, ribose and trehalose (at $1 \% \mathrm{w} / \mathrm{v})$ and salicin and starch (at $0.5 \% \mathrm{w} / \mathrm{v})$ in peptone-yeast extract broth as described previously (Brailsford $e t$ al., 1999). Isolates were also tested for the presence of preformed glycosidic enzyme activities ( $N$-acetyl- $\beta$-glucosaminidase, $N$-acetyl- $\beta$ galactosaminidase, $\alpha$-L-fucosidase, $\beta$-D-fucosidase, sialidase, $\beta$-glucosidase, $\alpha$-glucosidase, $\alpha$-arabinosidase, $\alpha$-galactosidase and $\beta$-galactosidase) with 4-methylumbelliferyl-linked fluorogenic substrates as described previously (Beighton et al., 1991). The catalase activity and ability of each isolate to grow in air was also determined.

Housekeeping genes. Six housekeeping genes [atpA (ATP synthase F1, alpha subunit, ANA_0169), rроB (DNA-directed RNA polymerase, beta subunit, ANA_1497), pgi (glucose-6-phosphate isomerase, ANA_0727), metG (methionyl-tRNA synthase, ANA_1898), gltA (citrate synthase I, ANA_1674) and gyrA (DNA gyrase, subunit A, ANA_2224)] were identified from the genome of A. naeslundii MG1 (http://cmr.jcvi.org/tigr-scripts/CMR/CmrHomePage.cgi). These genes were selected as they were present as single copies in the MG1 genome, were widely spaced on the chromosome and were of sufficient size for primer design to yield amplicons of $>450 \mathrm{bp}$. The primers used in the primary amplifications and for sequencing and amplicon sizes are shown in Table 2.

Gene amplification and DNA sequencing. To extract DNA from isolates, they were grown overnight on FAA and bacteria were washed in $2 \mathrm{M} \mathrm{NaCl}$. Cells were resuspended in TE buffer containing $0.5 \%$ Tween $20(\mathrm{pH} 8.0)$ and proteinase $\mathrm{K}$ was added to a final concentration of $200 \mu \mathrm{g} \mathrm{ml}^{-1}$ (Aas et al., 2005). The tubes were incubated at $55^{\circ} \mathrm{C}$ for $2 \mathrm{~h}$ and subsequently heated at $95{ }^{\circ} \mathrm{C}$ for $5 \mathrm{~min}$ to inactivate the proteinase K. DNA extracts were stored at $-20{ }^{\circ} \mathrm{C}$.

PCRs to amplify the individual genes were performed in a total volume of $15 \mu \mathrm{l}$ composed of $1 \mu \mathrm{l}$ DNA template, $0.2 \mu \mathrm{M}$ each primer, $2 \mathrm{mM}$ $\mathrm{MgCl}_{2}$ and Reddy-Mix (Thermo Scientific). Because of noticeable sequence variability and/or recurring high- $\mathrm{G}+\mathrm{C}$ regions, each gene was amplified simultaneously using multiple PCR primer sets (Table 2). After heating, DNA was amplified with 30 cycles and an annealing temperature of $53{ }^{\circ} \mathrm{C}$. Prior to sequencing, the PCR products were purified by adding $4 \mathrm{U}$ exonuclease I (Fermentas) and $1 \mathrm{U}$ shrimp alkaline phosphatase (Thermo Scientific) to each reaction and incubating at $37^{\circ} \mathrm{C}$ for $45 \mathrm{~min}$; the enzymes were then inactivated at $80{ }^{\circ} \mathrm{C}$ for 15 min. Amplicon sequencing of both strands was performed by using the ABI Prism BigDye Terminator Sequencing kit (Applied Biosystems) with 30 cycles of denaturation at $96{ }^{\circ} \mathrm{C}$ for $10 \mathrm{~s}$, annealing at $50{ }^{\circ} \mathrm{C}$ for $5 \mathrm{~s}$ and extension at $60{ }^{\circ} \mathrm{C}$ for $2 \mathrm{~min}$. Sequencing reaction products were run on an ABI sequencer 3730xl (Applied Biosystems). 
Table 1. Type and reference strains used in this study

Strains labelled Strömberg were kindly provided by Professor Nicolas Strömberg, University of Göteborg, Sweden; strains labelled CCUG were purchased directly from the Culture Collection of the University of Göteborg. A. viscosus NCTC $10951^{\mathrm{T}}$ was purchased from the National Collection of Type Cultures, HPA, Colindale, UK.

\begin{tabular}{|c|c|c|c|}
\hline Strain & Source & Clinical origin & Study no. \\
\hline \multicolumn{4}{|l|}{ Received as genospecies 1} \\
\hline P6N & Strömberg & Plaque & 96 \\
\hline Pn1GA & Strömberg & Plaque & 104 \\
\hline Pn16E & Strömberg & Plaque & 105 \\
\hline $\mathrm{P} 10 \mathrm{~N}$ & Strömberg & Plaque & 106 \\
\hline Pn6N & Strömberg & Plaque & 107 \\
\hline Pn20E & Strömberg & Plaque & 108 \\
\hline ATCC $12104^{\mathrm{T}}$ & Strömberg & Plaque & 109 \\
\hline $\mathrm{P} 5 \mathrm{~N}$ & Strömberg & Plaque & 110 \\
\hline P11N (=CCUG 33920) & CCUG & Plaque & 111 \\
\hline 461 (=CCUG 34725) & CCUG & Occlusal plaque & 112 \\
\hline TF 11 (=CCUG 35334) & CCUG & Blood (endocarditis) & 113 \\
\hline R709-03041/97 (=CCUG 37599) & CCUG & Cerebrospinal fluid & 114 \\
\hline \multicolumn{4}{|l|}{ Received as genospecies 2} \\
\hline $\mathrm{P} 2 \mathrm{G}$ & Strömberg & Plaque & 95 \\
\hline $\mathrm{P} 5 \mathrm{~K}$ & Strömberg & Plaque & 97 \\
\hline P6K & Strömberg & Plaque & 98 \\
\hline P7K & Strömberg & Plaque & 99 \\
\hline P8K & Strömberg & Plaque & 100 \\
\hline P9K & Strömberg & Plaque & 101 \\
\hline $\operatorname{Pn} 4 \mathrm{D}$ & Strömberg & Plaque & 102 \\
\hline $\operatorname{Pn} 5 \mathrm{D}$ & Strömberg & Plaque & 103 \\
\hline VPI $12593(=$ CCUG 34285)* & CCUG & Human abscess & 115 \\
\hline VPI D163E-3 (=CCUG 34286)* & CCUG & Gingival crevice (periodontitis) & 116 \\
\hline ATCC 27044 (A. viscosus serotype II $)^{*}$ & ATCC & Human sputum & 119 \\
\hline \multicolumn{4}{|l|}{ Received as genospecies WVA 963} \\
\hline PK1259 (=CCUG 33932) & CCUG & Subgingival plaque & 117 \\
\hline WVA $963(=$ CCUG 34287)* & CCUG & Subgingival plaque & 118 \\
\hline \multicolumn{4}{|l|}{ Received as $A$. viscosus } \\
\hline A. viscosus serotype I NCTC $10951^{\mathrm{T}_{\star}}$ & NCTC & Hamster & 120 \\
\hline
\end{tabular}

${ }^{*}$ Genotype determined by DNA-DNA relatedness (Johnson et al., 1990); others were determined by using genospecies-specific antisera (Putnins \& Bowden, 1993).

Sequence analysis. All DNA sequences were analysed, trimmed and aligned using BioEdit software (version 7.0.0; http://www.mbio.ncsu. edu/BioEdit/bioedit.html). Phylogenetic relationships between the type and reference strains and the human oral and clinical isolates were analysed using MEGA 3.1 (Kumar et al., 2004). Distances were calculated using Kimura's two-parameter model and, for clustering, the neighbour-joining method of Saitou \& Nei (1987) was employed using bootstrap values based on 500 replicates.

\section{RESULTS AND DISCUSSION}

\section{Differentiation of genospecies by sequence analysis}

The sequence heterogeneity within each gene required the use of sets of primers for each targeted gene to produce amplicons for use in nested PCRs. The pairs of sequencing primers successfully sequenced each of the gene fragments from the majority of organisms but, in a small number of cases, one of the initial amplification primers was required. Neighbour-joining trees for each of the six housekeeping genes (atpA, met $G, r p o B, g y r A$, pgi and $g l t A$ ) are shown in Fig. 1 and in Supplementary Fig. S1. There was very good agreement between the genotype of the isolate as received and the cluster with which each strain was associated on the basis of the partial gene sequences. The only difficulty was found with strains $\mathrm{P} 6 \mathrm{~N}, \mathrm{P} 10 \mathrm{~N}, \mathrm{P} 5 \mathrm{~N}$ and $\mathrm{P} 11 \mathrm{~N}$ (=CCUG 33920), which were received as genospecies 1, but which were found to align with the type and reference strains designated genospecies 2 with each of the six housekeeping genes. The initial assignment of these four strains to genospecies 1 was made on the basis of their 
Table 2. Primers used to amplify and sequence fragments of housekeeping genes investigated for their ability to identify members of $A$. naes/undii genospecies 1,2 and WVA 963

\begin{tabular}{|c|c|c|c|}
\hline Primer & Primer sequence sets $\left(5^{\prime}-3^{\prime}\right)$ & Sequencing primer $\left(5^{\prime}-3^{\prime}\right)$ & $\begin{array}{l}\text { Fragment } \\
\text { length (bp) }\end{array}$ \\
\hline \multicolumn{4}{|l|}{ atpA } \\
\hline AtpA-F & $\begin{array}{l}\text { TCGCCGAGTCCTACAAGC } \\
\text { ACACCATCCTCAACCAGAA } \\
\text { ACCCGAACAAGCAGGTG }\end{array}$ & CCCTGGAGTACACCACCAT & 474 \\
\hline AtpA-R & $\begin{array}{l}\text { CAGGTCGGAAGCGAACAT } \\
\text { CGGGTAGGGCGTGTACT } \\
\text { TCCTCGGTCTCGTCAGTGA }\end{array}$ & CGCCAGGGTGATCTTGAG & \\
\hline \multicolumn{4}{|c|}{ ( } \\
\hline GltA-F & $\begin{array}{l}\text { GCCAAGTCCTCGACCTTC } \\
\text { CGCCTACCTCCTCATCAA }\end{array}$ & CCAAGATGCCCACGATGAT & 552 \\
\hline GltA-R & $\begin{array}{l}\text { CGAACAGGGGTGTGAACAT } \\
\text { GGTGGAGCCGTCGTAAAC }\end{array}$ & GGCGGTCTCCTTGACGAT & \\
\hline \multicolumn{4}{|l|}{ gyrA } \\
\hline GyrA-F & $\begin{array}{l}\text { GCGACGAAGTTGAAGAGAT } \\
\text { GCCTCСTTCTCCAAGTCCT }\end{array}$ & GGTACACCGAGTGCAAGAT & 564 \\
\hline GyrA-R & $\begin{array}{l}\text { GCCGTAGTTGGTGAAGAAC } \\
\text { GCTCGTCGCCGTACTTCT }\end{array}$ & CGACCAGGGCGAGCATATT & \\
\hline \multicolumn{4}{|l|}{ metG } \\
\hline MetG-F & $\begin{array}{l}\text { GCCGACCGCAACAAC } \\
\text { GCCTGTCCTACGACCTGTTC } \\
\text { ACTTCATGGGCAAGGACAA }\end{array}$ & GAGGTCGTCTCCAGCG & 504 \\
\hline MetG-R & $\begin{array}{l}\text { CGGAGTCGGCGTAACG } \\
\text { ACTCGTCCAGCTTGGTGAA } \\
\text { CGGTGATGATCGGGTAGC }\end{array}$ & CAGGAAGGGCGAGAGCAT & \\
\hline \multicolumn{4}{|c|}{ 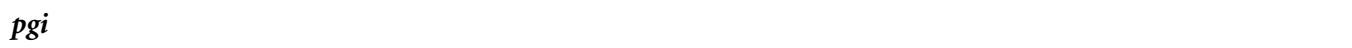 } \\
\hline Pgi-F & $\begin{array}{l}\text { GAGCTGGGAGACCTCTACAT } \\
\text { CGACCTGTCCAAGAACCT }\end{array}$ & GCGAGCACATCAACATCA & 531 \\
\hline Pgi-R & $\begin{array}{l}\text { TGGTGGATGAGCTGGTAGA } \\
\text { GGAAGTCGGCGAAGTTCT }\end{array}$ & CACCCACCCAGTTCCAGAA & \\
\hline rpoB & & & \\
\hline RpoB-F & $\begin{array}{l}\text { CGAGGAGCCGAAGTACA } \\
\text { CGTCACCGTCTTTCTG } \\
\text { CCTGGGCATGGACGAGT }\end{array}$ & GGACGAGGACCGCAAGAT & 491 \\
\hline RpoB-R & $\begin{array}{l}\text { GGCGTCCTCGTAGTTGA } \\
\text { CGTAGTGCGAGGTGTGGA } \\
\text { GGTTGTTCTGGTCCATGA }\end{array}$ & TGGGAGGTGCCGAAGAAC & \\
\hline
\end{tabular}

agglutination reactions with genospecies-specific antisera, but the haemagglutination reactions of these strains were distinct from others designated genospecies 1 , as they failed to haemagglutinate intact human, goat, sheep or horse red blood cells while the other strains designated genotype 1 haemagglutinated these cells (Hallberg et al., 1998). The present data suggest that genospecies-specific antisera (Putnins \& Bowden, 1993) may not always be reliable in identifying genospecies 2 isolates, as some may be mis- identified as genospecies 1, and reassessment of previous data might be necessary. It also follows that there is greater homogeneity within the haemagglutination reactions of genospecies 1 than was previously recognized.

The dendrograms had similar overall topographies but differed with respect to the distance between genospecies 1 and genospecies 2 clusters and the sequence heterogeneity within the genospecies clusters. The finding that the tree

Fig. 1. Neighbour-joining tree showing taxonomic relationships between type and reference strains of $A$. naes/undii, $A$. oris sp. nov., $A$. johnsonii sp. nov. and $A$. viscosus and oral and clinical isolates determined by partial gene sequence analysis of atpA (a) and metG (b). Type and reference strains are identified by study numbers (see Table 1) and indicated as follows: $\bullet$, $A$. oris sp. nov. (genospecies 2); $\mathbf{\square}, A$. naeslundii (genospecies 1); $\diamond, A$. viscosus; $\boldsymbol{\Delta}, A$. johnsonii sp. nov. (genospecies WVA 963). Bootstrap values are indicated at corresponding nodes. See Supplementary Fig. S1 for dendrograms for $r p o B$, gyrA, pgi and gltA. Bars, 0.005 substitutions per site. 

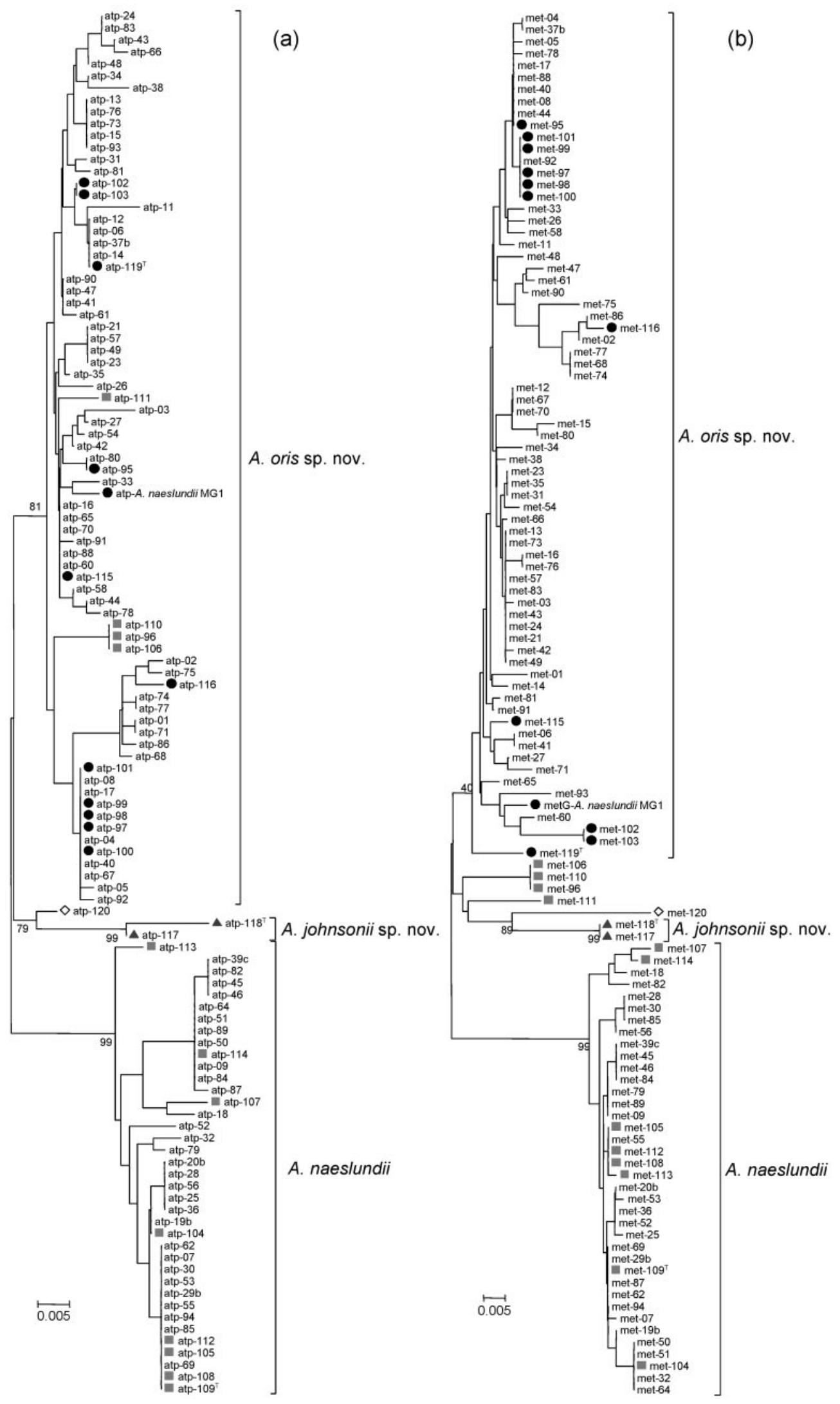
topologies are not identical does not limit their use in assigning isolates to a particular species, since various factors may account for the individual tree topologies, including the level of information content, different rates of evolution due to selective pressures and the length of the partial sequences that are compared (Christensen et al., 2004). The variation in the discriminatory power of individual genes suggests the use of multiple genes for the most robust identification of isolates (Naser et al., 2007).

In all dendrograms, the two genospecies WVA 963 strains were distinct from genospecies 1 and 2 strains, confirming the conclusions from DNA-DNA relatedness data that these strains are genetically distinct (Johnson et al., 1990) and refuting the suggestion that isolates identified as serotype WVA 963 should be included in genospecies 2 (Putnins \& Bowden, 1993). The single rodent A. viscosus serotype I strain (the type strain) was also distinct from the A. naeslundii strains.

The different housekeeping genes were not equally able to separate the genospecies. The sequences of atpA were the most homogeneous for genospecies 2, and all genospecies were well separated. The met $G$ gene also exhibited the greatest sequence difference between genospecies 1 and 2; each genospecies was characterized by low heterogeneity within the cluster and the hamster strain and genotype WVA 963 strains were readily differentiated. The $r p o B$ gene was less heterogeneous in genospecies 1 than in genospecies 2 but both clusters, and genospecies WVA 963 and the hamster strain, were well separated. With gyrA, genospecies 1 and 2 could be readily differentiated but, within each genospecies, there was considerable sequence diversity. The sequence variations for $p g i$ within the genospecies and the hamster strain of A. viscosus may not be sufficient to permit reliable identification of the isolates. The phylogenetic tree of gltA indicated greater homogeneity within strains of genospecies 1 but also greater heterogeneity within genospecies 2, which were not as well separated from genospecies 1 strains, or from $A$. viscosus or genospecies WVA963, as they were with atpA and metG. Overall, the genes aptA, met $G, r p o B$ and gyrA exhibited the most discrete clusters for genospecies 1 and 2. In each dendrogram, the two strains of genospecies WVA 963 were positioned between the other two genospecies and always occurred together. The animal strain A. viscosus NCTC $10951^{\mathrm{T}}$ branched either together with the strains of genospecies WVA 963 with atpA, gyrA, met $G$ and pgi or separately between genospecies 1 and 2 with gltA and rpoB.

The partial sequences of all six housekeeping genes differed markedly in the other five oral Actinomyces species investigated. PCR products or sequence data from both strands could not be obtained for all strains. For atpA, sequence data were obtained only for A. meyeri ATCC $35568^{\mathrm{T}}$, A. georgiae R11726 and A. gerencseriae ATCC $23860^{\mathrm{T}}$, but the sequence similarity was $<91 \%$ with the $A$. naeslundii genotype strains. met $G$ sequences were obtained for A. israelii ATCC $12102^{\mathrm{T}}$ and A. odontolyticus NCTC $9935^{\mathrm{T}}$, and they had $<86 \%$ similarity with the $A$. naeslundii strains, while an $r p o B$ sequence was obtained only for A. israelii ATCC $12102^{\mathrm{T}}$, which had $<90 \%$ similarity. The gene gyrA could not be sequenced in $A$. israelii ATCC $12102^{\mathrm{T}}$ or A. georgiae R11726, and the other strains had $<87 \%$ sequence similarity with the $A$. naeslundii genotype strains and, with $p g i$, no sequence could be obtained for A. israelii ATCC $12102^{\mathrm{T}}$ and the similarity between the species and the A. naeslundii genotypes was $<92 \%$. Sequences for gltA were only obtained from A. israelii ATCC $12102^{\mathrm{T}}$ and A. gerencseriae ATCC $23860^{\mathrm{T}}$, and they exhibited $<88 \%$ similarity with the A. naeslundii genotype strains.

On the basis of discrimination between the 12 reference and type strains, all of the sequences from the oral and clinical isolates could be assigned to either A. naeslundii genospecies 1 or 2 . The non-oral clinical isolates (study numbers 83-94) and the oral clinical isolates (study numbers 1-82) were each detected in the same cluster with each of the genes. Of the 89 oral and non-oral clinical isolates, 59 were identified as genospecies 2 and 30 were identified as genospecies 1 .

\section{Phenotypic characterization of the resulting clusters}

For phenotypic description, all isolates were tested with the API Rapid ID32A kit, and additional carbohydrate fermentations and enzyme reactions were carried out. None of the 115 isolates were identified as A. naeslundii or A. viscosus at an acceptable level using the API Rapid ID32A kit. The percentage of positive reactions for each test for the three A. naeslundii genospecies, as assigned from the phylogenetic analysis, is listed in Table 3. No distinctive patterns enabled the use of these tests to distinguish between the genospecies, confirming the extensive phenotypic data reported previously (Johnson et al., 1990).

\section{Description of Actinomyces oris sp. nov.}

Actinomyces oris (o'ris. L. gen. n. oris of the mouth).

Contains strains previously identified as A. naeslundii serotypes II, III and NV and A. viscosus serotype II. Formerly known as Actinomyces naeslundii genospecies 2 and, on the basis of conventional phenotypic testing, is indistinguishable from other $A$. naeslundii genotypes. Biochemical and physiological characteristics are as reported for $A$. naeslundii genospecies 2 (Johnson et al., 1990) supplemented with those reported here. The G+C content of the type strain is $66 \mathrm{~mol} \%$. Actinomyces oris may be differentiated from closely related species on the basis of sequence comparisons of partial gene sequences of atpA or metG. 
Table 3. Biochemical properties of $A$. naes/undii genospecies 1, 2 and WVA 963

Data are percentages of strains giving positive reactions. Isolates were assigned to individual genospecies on the basis of their positions in phylogenetic trees calculated using partial gene sequences of atpA and metG. All strains were positive for activity of proline, phenylalanine and leucine arylamidases in the API Rapid ID32A kit and for neuraminidase (sialidase) and $\alpha$-glucosidase activity using fluorogenic substrates, and all exhibited aerobic growth. All strains were negative for arginine dihydrolase, $\beta$-galactosidase-6-phosphate, $\alpha$ arabinosidase, $\beta$-glucuronidase, $N$-acetyl- $\beta$-glucosaminidase, glutamic acid decarboxylase, $\alpha$-fucosidase and for activity of arginine, leucylglycine, pyroglutamic acid, histidine, glutamylglutamic acid and serine arylamidases in the API Rapid ID32A kit and for $N$-acetyl- $\beta$-D-galactosaminidase and $N$-acetyl- $\beta$-Dglucosaminidase activities using fluorogenic substrates, none fermented arabinose or mannitol using the previously described method (Brailsford et al., 1999) and none produced indole.

\begin{tabular}{|c|c|c|c|}
\hline Phenotypic test & $\begin{array}{l}\text { Genospecies } 1 \\
\text { (A. naeslundii) } \\
\quad(n=42)\end{array}$ & $\begin{array}{c}\text { Genospecies } 2 \\
(A . \text { oris } \text { sp. nov. }) \\
(n=70)\end{array}$ & $\begin{array}{c}\text { Genospecies WVA } 963 \\
\text { (A. johnsonii sp. nov. }) \\
(n=2)\end{array}$ \\
\hline \multicolumn{4}{|l|}{ API Rapid ID32A } \\
\hline Urease & 0 & 1 & 50 \\
\hline$\alpha$-Galactosidase & 44 & 44 & 100 \\
\hline$\beta$-Galactosidase & 75 & 67 & 100 \\
\hline$\alpha$-Glucosidase & 88 & 81 & 100 \\
\hline$\beta$-Glucosidase & 83 & 61 & 100 \\
\hline Mannose fermentation & 0 & 1 & 50 \\
\hline Raffinose fermentation & 2 & 4 & 0 \\
\hline Nitrate reduction & 98 & 96 & 100 \\
\hline Alkaline phosphatase & 0 & 0 & 50 \\
\hline Tyrosine arylamidase & 98 & 97 & 100 \\
\hline Alanine arylamidase & 0 & 1 & 0 \\
\hline Glycine arylamidase & 0 & 3 & 0 \\
\hline \multicolumn{4}{|l|}{ Other methods } \\
\hline \multicolumn{4}{|l|}{ Fermentation of: } \\
\hline Cellobiose & 31 & 9 & 0 \\
\hline Fructose & 98 & 99 & 50 \\
\hline Glycogen & 5 & 40 & 100 \\
\hline Inositol & 100 & 93 & 50 \\
\hline Lactose & 71 & 67 & 100 \\
\hline Ribose & 0 & 21 & 100 \\
\hline Salicin & 64 & 23 & 0 \\
\hline Starch & 2 & 16 & 50 \\
\hline Trehalose & 50 & 43 & 50 \\
\hline Aesculin hydrolysis & 62 & 13 & 0 \\
\hline Catalase production & 10 & 70 & 50 \\
\hline$\beta$-D-Fucosidase & 90 & 91 & 100 \\
\hline$\alpha$-L-Fucosidase & 12 & 0 & 100 \\
\hline$\beta$-Glucosidase & 100 & 90 & 100 \\
\hline$\alpha$-Galactosidase & 100 & 96 & 100 \\
\hline$\alpha$-Arabinosidase & 88 & 93 & 100 \\
\hline$\beta$-Galactosidase & 88 & 93 & 100 \\
\hline
\end{tabular}

The type strain is ATCC $27044^{\mathrm{T}}\left(=\mathrm{CCUG} 34288^{\mathrm{T}}\right)$, isolated from human sputum.

\section{Description of Actinomyces johnsonii sp. nov.}

Actinomyces johnsonii (john.so' ni.i. N.L. gen. n. johnsonii of Johnson, named after the American molecular taxonomist John L. Johnson, who undertook extensive studies on the genetic relationships between oral actinomyces).
Contains strains previously identified as A. naeslundii serotype WVA 963. Formerly known as Actinomyces naeslundii genospecies WVA 963 and, on the basis of conventional phenotypic testing, is indistinguishable from other A. naeslundii genotypes. Biochemical and physiological characteristics are as reported for A. naeslundii genospecies WVA 963 (Johnson et al., 1990). The G+C content of the type strain is $67 \mathrm{~mol} \%$. Actinomyces johnsonii may be differentiated from closely related species 
on the basis of sequence comparisons of partial gene sequences of atpA or met $G$.

The type strain is ATCC $49338^{\mathrm{T}}\left(=\right.$ CCUG $\left.34287^{\mathrm{T}}\right)$, isolated from the gingival crevice of a healthy child.

\section{Emended description of Actinomyces naes/undii Thompson and Lovestedt 1951}

Contains strains previously identified as A. naeslundii serotype I. Formerly known as Actinomyces naeslundii genospecies 1 and, on the basis of conventional phenotypic testing, is indistinguishable from other $A$. naeslundii genotypes. Biochemical and physiological characteristics are as reported for A. naeslundii genospecies 1 (Johnson et al., 1990) supplemented with those reported here. The $\mathrm{G}+\mathrm{C}$ content of the type strain is $66 \mathrm{~mol} \%$. Actinomyces naeslundii may be differentiated from closely related species on the basis of sequence comparisons of partial gene sequences of atpA or metG.

The type strain is ATCC $12104^{\mathrm{T}}=$ NCTC $10301^{\mathrm{T}}=$ CCUG $2238^{\mathrm{T}}$, isolated from a human sinus.

\section{ACKNOWLEDGEMENTS}

This work was supported in part by King's College London Dental Institute and the Wellcome Trust (grant no. GR076381).

\section{REFERENCES}

Aas, J. A., Paster, B. J., Stokes, L. N., Olsen, I. \& Dewhirst, F. E. (2005). Defining the normal bacterial flora of the oral cavity. J Clin Microbiol 43, 5721-5732.

Beighton, D., Hardie, J. M. \& Whiley, R. A. (1991). A scheme for the identification of viridans streptococci. J Med Microbiol 35, 367-372.

Brailsford, S. R., Tregaskis, R. B., Leftwich, H. S. \& Beighton, D. (1999). The predominant Actinomyces spp. isolated from infected dentin of active root caries lesions. J Dent Res 78, 1525-1534.

Christensen, H., Kuhnert, P., Olsen, J. E. \& Bisgaard, M. (2004). Comparative phylogenies of the housekeeping genes atpD, infB and $r p o B$ and the 16S rRNA gene within the Pasteurellaceae. Int J Syst Evol Microbiol 54, 1601-1609.

Ellen, R. P. (1976). Establishment and distribution of Actinomyces viscosus and Actinomyces naeslundii in the human oral cavity. Infect Immun 14, 1119-1124.

Fillery, E. D., Bowden, G. H. \& Hardie, J. M. (1978). A comparison of strains of bacteria designated Actinomyces viscosus and Actinomyces naeslundii. Caries Res 12, 299-312.
Gerencser, M. A. \& Slack, J. M. (1976). Serological identification of Actinomyces using fluorescent antibody techniques. J Dent Res 55, A184-A191.

Hallberg, K., Hammarström, K. J., Falsen, E., Dahlén, G., Gibbons, R. J., Hay, D. I. \& Strömberg, N. (1998). Actinomyces naeslundii genospecies 1 and 2 express different binding specificities to $\mathrm{N}$-acetylbeta-D-galactosamine, whereas Actinomyces odontolyticus expresses a different binding specificity in colonizing the human mouth. Oral Microbiol Immunol 13, 327-336.

Hoshino, T., Fujiwara, T. \& Kilian, M. (2005). Use of phylogenetic and phenotypic analyses to identify nonhemolytic streptococci isolated from bacteremic patients. J Clin Microbiol 43, 6073-6085.

Johnson, J. L., Moore, L. V., Kaneko, B. \& Moore, W. E. (1990). Actinomyces georgiae sp. nov., Actinomyces gerencseriae sp. nov., designation of two genospecies of Actinomyces naeslundii, and inclusion of A. naeslundii serotypes II and III and Actinomyces viscosus serotype II in A. naeslundii genospecies 2. Int J Syst Bacteriol 40, 273-286.

Jumas-Bilak, E., Carlier, J.-P., Jean-Pierre, H., Teyssier, C., Gay, B., Campos, J. \& Marchandin, H. (2004). Veillonella montpellierensis sp. nov., a novel, anaerobic, Gram-negative coccus isolated from human clinical samples. Int J Syst Evol Microbiol 54, 1311-1316.

Kumar, S., Tamura, K. \& Nei, M. (2004). MEGA3: integrated software for molecular evolutionary genetics analysis and sequence alignment. Brief Bioinform 5, 150-163.

Lane, D. J. (1991). 16S/23S rRNA sequencing. In Nucleic Acid Techniques in Bacterial Systematics, pp. 115-175. Edited by E. Stackebrandt \& M. Goodfellow. Chichester: Wiley.

Li, J., Helmerhorst, E. J., Leone, C. W., Troxler, R. F., Yaskell, T., Haffajee, A. D., Socransky, S. S. \& Oppenheim, F. G. (2004). Identification of early microbial colonizers in human dental biofilm. $J$ Appl Microbiol 97, 1311-1318.

Marsh, P. D. \& Martin, M. V. (1999). Oral Microbiology, 4th edn. Oxford: Butterworth-Heinemann.

Naser, S. M., Dawyndt, P., Hoste, B., Gevers, D., Vandemeulebroecke, K., Cleenwerck, I., Vancanneyt, M. \& Swings, J. (2007). Identification of lactobacilli by pheS and rpoA gene sequence analyses. Int J Syst Evol Microbiol 57, 2777-2789.

Putnins, E. E. \& Bowden, G. H. (1993). Antigenic relationships among oral Actinomyces isolates, Actinomyces naeslundii genospecies 1 and 2, Actinomyces howellii, Actinomyces denticolens, and Actinomyces slackii. J Dent Res 72, 1374-1385.

Saitou, N. \& Nei, M. (1987). The neighbor-joining method: a new method for reconstructing phylogenetic trees. Mol Biol Evol 4, 406-425.

Tang, G., Yip, H. K., Luo, G., Cheung, B. P., Shen, S. \& Samaranayake, L. P. (2003). Development of novel oligonucleotide probes for seven Actinomyces species and their utility in supragingival plaque analysis. Oral Dis 9, 203-209.

Thompson, L. \& Lovestedt, S. A. (1951). An Actinomyces-like organism obtained from the human mouth. Proc Staff Meet Mayo Clin 26, 169-175. 